\title{
O artista/docente: ou o que a arte pode aprender com a educação (3) 1
}

ISABEL MARQUES ${ }^{2}$

Agradeço Ana Mundim pelo convite a escrever este artigo e a Fábio Brazil pela leitura e discussão do mesmo.

2 Pedagoga pela USP, Mestre em Dança pelo Laban Centre (hoje Trinity Laban) e doutora em Educação pela USP. Diretora do Caleidos Cia. de Dança e do Instituto Caleidos, em São Paulo, capital. Autora dos livros "Ensino de dança hoje" (Cortez, 6ª edição), "Dançando na escola", (Cortez, 6ª edição) "Linguagem da dança: arte e ensino" (Cortez, 2a - edição, finalista do Jabuti 2011), "Interações: criança, dança, escola" (Blucher, finalista do Jabuti 2013), "Arte em Questões”, com Fábio Brazi (Cortez, 2a. edição, finalista do Jabuti 2013). 


\section{- RESUMO}

Este artigo relê e ressignifica o trabalho de doutorado da autora, defendido em 1996, na Faculdade de Educação da USP no qual cunhou o termo artista/docente tratando de entendê-lo como uma rede de relações entre a arte, o ensino e a sociedade. Dezoito anos mais tarde, a autora parte do texto original da pesquisa para reconsiderar, questionar e ampliar conceitos hoje implícitos e implicados em sua prática artística. Este é o terceiro artigo da série: o que a arte pode aprender com a educação? tratando de imprimir um olhar às avessas na formação do artista.

\section{- PALAVRAS-CHAVE}

Educação, dança, artista, docente, contemporaneidade.

\section{- ABSTRACT}

This article revises the author's doctoral research from 1996 at the University of São Paulo in which the concept of artist/teacher was launched trying to understand it in a interwoven net between dance, teaching and society. Eighteen years later, the author starts at the original research in order to reconsider, question and expand the concepts today inserted in her artistic practice. This is the third article of a series: what can art learn from education? trying to imprint a new way to understand the artist's education.

\section{- KEYWORDS}

Education, dance, artist, teacher, contemporary society.

\section{Primeiras palavras}

Este é o terceiro artigo de uma série em que venho discutindo e refletindo sobre as influências e as contribuições da Educação para a Arte, e não o contrário, como comumente se faz. Tendo uma carreira híbrida, percebo que, mesmo embrionariamente, as contribuições do sistema da arte para a educação formal já têm um caminho percorrido e já aponta para outros a percorrer. O contrário, no entanto, ainda permanece nebuloso: em que medida a arte encontra valores e referências na educação? Em que medida ser professor afeta, transforma e contribui com a carreira e o trabalho do artista?

Tratando de problematizar uma série de preconceitos em relação ao trabalho pedagógico no meio artístico busco aqui afirmar e discutir como atuar no campo da educação e do ensino faz com que a arte que se produz seja diferente e, até mesmo, diferenciada. Neste artigo, faço um recorte conceitual revisitando a questão do artista/docente deste ponto de vista.

Cunhei o termo artista/docente em minha pesquisa de doutorado defendida em 1996, na Faculdade de Educação da USP, entendendo que "o artista/docente é aquele que, não abandonando suas possibilidades de criar, interpretar, dirigir também tem como função e busca explícita a educação em seu sentido mais amplo. Ou seja, abre-se a possibilidade de que processos de criação artística possam ser revistos e repensados como processos também explicitamente educacionais" (MARQUES, 1999), ênfase da autora. Neste artigo, releio e rediscuto esta proposição à luz de vivências e pesquisa artísticas. 


\section{Chovendo no molhado: releituras}

Desde 1989, as relações entre a dança e a educação são o principal foco de meu trabalho docente, artístico e de pesquisa formal. Apartados, dança e educação têm sido historicamente compreendidas pelo senso comum como áreas de conhecimento isoladas, com diálogos frágeis e preconceitos transversalizados. Defendo há mais de 25 anos que dança e educação devem dialogar. Para além disso, afirmo que dança/educação deve ser compreendida e vivenciada como uma área de conhecimento híbrida, relacional (vide MARQUES, 1996, 2009, 2010a, 2010b etc.).

Mesmo "chovendo no molhado", reafirmo neste artigo o papel educacional (não pedagógico) da dança cênica, ou seja, retomo a premissa de que a arte em suas mais diversas manifestações, educa (vide MARQUES, 2010b etc.), tendo com isso valor sociopolítico-cultural inestimável (vide MARQUES; BRAZIL, 2011).

A consciência sociopolítica de muitos artistas contemporâneos, que se reflete na consciência da relação artista-público (e a preocupação com esta relação), é em si um ato político e, portanto, educacional. Como sempre afirmou Paulo Freire, a educação é em si um ato político. Portanto, a arte compromissada com as relações entre artista/produção/público é também um ato educacional, uma vez que é político, mas não necessariamente pedagógico.

Nesse sentido, é preciso fazer novamente a distinção entre educação e ensino, de modo a não escolarizar a arte e tampouco mutilar a função social do artista. O conceito de muitos artistas de que educação se resume ao ensino não só denota profunda ingenuidade (no sentido freiriano) por parte dos mesmos, mas, sobretudo, imprime na produção artística os traços indeléveis de certo egocentrismo e não raramente o descaso com o público.

Para o senso comum, o papel da educação na dança - entendida somente como ensino - se resume a "passar" técnicas e passos, fazer exercícios e decorar sequências. Este tipo de enfoque delega à educação status social secundário, função "preparatória" da arte, sem glamour ou possibilidade de reconhecimento. Talvez seja também por isso que muitos artistas entendam que relacionar sua arte à educação seja apequenar sua arte e até torná-la degradante.

Não raramente, para o artista convencional, ministrar aulas de dança não passa, portanto, de uma alternativa financeira que interrompe o fluxo do fazer artístico. Relendo hoje esta questão, já há tantos anos postulada, vejo que o próprio artista, com concepções de educação altamente comprometidas com o senso comum, não tem a capacidade e a clareza de compreender o quanto as relações educacionais - $\mathrm{e}$ até mesmo de ensino e aprendizagem - influenciam, contaminam e podem propor possibilidades para o fazer/pensar artísticos. Nessa releitura, proponho que as transformações das/nas relações pedagógicas podem ser compreendidas como fatores de transformação da própria arte.

Nessa linha de raciocínio, há pelo menos duas décadas também discuto a máxima de que "basta ser artista para ser professor", não, não basta. As transformações que não acontecem em salas de aula de dança, ou seja, a perpetuação da mesmice solidificada a que ainda assistimos na grande maioria das escolas de dança, se dá, principalmente, pelo preconceito ou descaso dos artistas em relação à educação/ ensino. Negando-se a rever conceitos de educação e de ensino e aprendizagem, muitos artistas reproduzem acriticamente aquilo que aprenderam tacitamente com 
seus mestres. Criam sequências novas, mas com sequelas eternas para os alunos e crenças antiquadas no que diz respeito à educação do ser/estar contemporâneo. Se houver qualquer relação entre o ensino de dança e um processo de educação crítico e transformador, não, não basta ser artista para ser professor.

Do meu ponto de vista, a formação do artista é e deve ser diferente - porém complementar - da formação do educador, do professor, do oficineiro, do "orientador" (vide MARQUES, 1996). No entanto, o que se assiste de fato hoje são jovens recém saídos de projetos sociais e/ou governamentais, tendo tido experiência de duas ou três aulas por semana de repertórios de dança, já sendo contratados para ministrar aulas em ONGs e até mesmo no contra turno de escolas formais. Ainda vemos academias de dança contratando seus alunos "mais experientes" para ministrar aulas para crianças e adultos iniciantes, sem que tenham tido qualquer tipo de preparo pedagógico. Assistimos a artistas com carreiras reconhecidas e sem qualquer tipo de contato com a literatura pedagógica atualizada fundando e difundindo seus "métodos de ensino".

Prevalece ainda o senso comum - das rodas de danças urbanas às salas de dança do ensino superior - que o dito "bom artista" é necessariamente um bom professor. Vejo hoje que isso se dá, justamente, pela negação e pelo imenso abismo que há entre as áreas de educação e arte em nosso país. O papel do professor de dança raramente é questionado pelos artistas que ensinam, assim como sua forma de ensinar. Mas, creio, há uma lógica interna nessa forma de pensar: se ensinar e aprender dança se reduz a copiar, o melhor professor realmente é aquele que dança bem, ele é o corpo mais adequado para que se copie. Em pleno século XXI, ainda podemos concordar que aprender a dançar é aprender a copiar bem "bons corpos"? Mais além: se aprendo a dançar copiando, que artista/cidadão me torno? As relações entre propostas pedagógicas e formação do próprio artista/cidadão precisam ser discutidas, pensadas e repensadas.

Desde 1989 venho também refletindo a respeito do binômio dança/educação em função da máxima do "quem sabe faz, quem não sabe ensina". No ensino superior isso se traduz muito bem quando alunas "menos talentosas" são "encaminhadas" para a Licenciatura (vide MARQUES, 1996). Essas ações carregam o preconceito socialmente constituído de que ser professor é mais fácil, uma carreira com exigências menores, portanto, para artistas também "menores". Como já coloquei em pauta essa discussão inúmeras vezes, permito-me somente colocar de novo uma pergunta extremamente simples: se o professor não sabe, como vai ensinar? Afirmo que talvez seja exatamente o contrário, quem sabe mais, este sim, deveria ensinar - quem não sabe, dança (permitindo-me o trocadilho do ditado popular). Não cabe aqui, obviamente, pensarmos num artista pouco conhecedor de sua arte - puro, intuitivo, genuíno - com também não cabe postularmos aqui um professor meramente erudito e sem qualquer experiência em dança enquanto arte - o acadêmico que jamais pisou num palco.

Aqui, afirmo mais uma vez que as atribuições e amplitude de conhecimento requeridas do professor que atua na escola formal são muitas vezes maiores do que as necessidades de conhecimento de um artista especializado (vide Marques, 2010a). Enquanto o artista especializado pode focar e recortar seu foco de atuação (por exemplo, o butoh, a improvisação etc.), o professor que ensina dança em escolas formais deve "dar conta" de todas as áreas de conhecimento da dança (da anatomia à sociologia da dança, passando por técnicas, processos de criação etc.). A primeira pergunta, logicamente, é: estão preparados para isso? A segunda, mais ligada ao 
tema deste artigo, não estará o professor que dispõe de um vasto leque de possibilidades de conhecimento e práticas que compartilha com seus alunos também mais aberto, flexível e preparado para processos de criação artística?

A realidade da grande maioria das escolas formais, no entanto, ainda está longe de vislumbrar esse quadro de professores. Artistas licenciados com leque aberto de conhecimentos e práticas nem sempre ensinam nas escolas formais, quer por falhas na legislação, quer por questões salariais ou de interesse pessoal. De fato, a dança nas escolas formais ainda se processa em grande parte do país via professores de Educação Física, Arte e Pedagogia.

Dada essa realidade, desde 1989, quando defendi pesquisa de Mestrado, e, posteriormente, trabalhando com a equipe de Arte durante a gestão Paulo Freire na Secretaria Municipal de Educação de São Paulo nos anos de 1991-993, defendo que a experiência, a vivência, o fazer artístico refletido e contextualizado são condições si ne qua non para ensinar dança nas escolas formais. Ou seja, defendo que a arte deve contaminar e fazer parte da vida dos professores.

Hoje isso parece uma obviedade, obviedade que não quer dizer realidade sistemática, obviedade esta que não se confirma nos bancos escolares. Professoras com calça justa (às vezes saias longas, também justas), vestindo sapatos derrapantes que se recusam a tirar, com corpos rígidos e desconhecidos delas mesmas costumam oferecer "atividades" de dança em suas salas de aula - com aval social. Se por um lado o artista comum se esquiva das relações com a educação (teorias e práticas), é fato também que pedagogos professores, pautados pelo mesmo senso comum, também se esquivam de relações complexas e mais profundas com a arte da dança. Arte e educação continuam apartadas. O papel do docente continua apartado do papel do artista - também com aval social.

Tampouco seria grande novidade sugerir neste artigo que a escola formal deve dialogar com os contextos sociopolítico-culturais em que está inserida, pois Paulo Freire já pontuava essa questão desde a década de 1960. Nesse sentido, no campo da dança, creio que é também "chover no molhado" dizer que as transmutações da arte na contemporaneidade deveriam ser o ponto de partida para revolucionar também as salas de aula de dança, venho argumentado isso desde 1991.

No entanto, nem as grandes transmutações que vêm ocorrendo desde a década de 1950 no sistema da arte da dança, sequer tangenciam as salas de aulas e as questões pedagógicas ali imbricadas - isso é perceptível das escolas formas às aulas das companhias de dança. Claro, há sempre valiosíssimas exceções que, inclusive, referendam o pensamento de que as transformações no sistema da arte devem dialogar com o sistema educacional. Esses exemplos nos dizem que isso é possível e desejável.

Quando a dança é ensinada nas escolas e fora delas, ainda segue o conceito de ensino e da arte do século XVIII, seja essa dança uma dança "dos alunos" (danças urbanas, por exemplo), da mídia, ou um repertório de danças populares brasileiras. Nesses casos, a dança aparece como sinônimo de repertório acabado, passos sequenciados a serem copiados e apresentados. Há também escolas que já trabalham com possibilidades de compreensão do corpo, de criação e produção de dança, com produções artísticas que, não raramente, caem no laissez-faire artístico das décadas de 1960-70. O conceito de arte e a forma de ensiná-la nas escolas formais -e em inúmeras situações de ensino informais também - encontram-se, ainda, em gran- 
de parte, estanques e anacrônicas (vide MARQUES, 1996).

A arte contemporânea, ao contrário disso, pressupõe um público que seja articulado, informado, sensível às proposições dos artistas; o público tende a ser incorporado aos trabalhos que não mais "mostram o mundo" e sim balizam sua construção (Lebrun, 1983). O público passa a ser o realizador daquilo que os projetos anunciam (FAVARETTO, 1985).

A partir desta constatação (aqui bem resumida), ao finalizar minha pesquisa de doutorado em 1996, tive clareza de que diálogos mais profícuos entre o sistema da arte e o sistema educacional seriam condição para a transformação do ensino de dança nas escolas. Em decorrência disto, argumentei e argumento em prol da necessidade de repensar os papéis de professor e de artista tanto no sistema da arte quanto nos meios educacionais e pedagógicos. Ou seja,

em função das transformações radicais ocorridas no mundo da arte/dança desde as décadas de 60 e 70, acredito estarmos no momento de repensar a função do artista que se torna também professor, ou do professor que quer continuar atuando como artista. seria importante não reforçar a ausência total de diálogo entre o mundo da arte e o mundo da educação na própria atuação do professor (MARQUES, 1999, p. 60).

Obviamente, o sistema escolar brasileiro, tal qual se encontra, tem exercido de forma espetacular sua função de manutenção de estruturas político-sociais, sendo a escolarização e a banalização da arte personagens importantes desse roteiro (vide MARQUES, 1996). Do mesmo modo, o artista/docente, tal qual discutiremos, não é bem vindo em um sistema fechado, retrógrado, preguiçoso e conservador que deseja perpetuar a ingenuidade, o senso comum e o consumismo. Por isso, sempre afirmei, transformar a dança/arte na escola é também transformar a própria escola. Não retomarei aqui essa discussão.

Retomo, isto sim, a proposta triangular de Ana Mae Barbosa, iniciada na década de 1980. Em suas incontáveis publicações, Barbosa (1991, 2010 etc.) deu um passo sem volta na literatura da arte/educação. Entre muitas de suas contribuições, coloca-se a premência de que estudantes e professores frequentem arte e que a frequentação deve necessariamente fazer parte do currículo escolar. A autora estabelece a necessidade de diálogos concretos entre a arte produzida na escola e a arte produzida socialmente.

Partilhando das ideias de Barbosa, em 1996, levanto outra questão já relacionada à reflexão sobre o artista/docente. "Meu questionamento central é [era] se o professor não poderia também atuar como artista e o artista como professor numa mesma atividade, seja ela artística ou docente" (MARQUES, 1999, p. 60).

Tendo esse questionamento em vista, o artista/docente, tal qual proponho, não se configura como um professor que dança, ou que mantém uma carreira artística paralela às suas atividades docentes. $O$ artista/docente é, tampouco, um artista que ensina nas horas vagas de seu trabalho artístico. Em minha proposta e carreira profissional, o artista/docente constitui-se no hibridismo, assim como a dança e a educação. O artista/docente é aquele que, numa mesma proposta, dança e educa: educa dançando e dança educando, consciente das duas ações fundidas que exerce.

Conforme já argumentei anteriormente, sugiro que exista uma 
ponte de via dupla entre a instituição escolar e o mundo da arte [que tenha] como interlocutor o próprio professor. Dançando, ele faz, aprecia, contextualiza a arte e o ensino com seus alunos. O papel do professor de dança não seria, portanto, somente o de um intermediário entre estes mundos - a dança, a escola, a sociedade - ele seria também uma das fontes vivas para experimentarmos de maneira direta esta relação (ibid).

Se por um lado proponho que em sala de aula o professor não abandone seu corpo artístico e faça de sua arte pessoal propostas e proposições pedagógicas, minha carreira artística tem sido alimentada por esse conceito (e prática) de artista/ docente às avessas: o trabalho cênico é fruto de cuidadosa reflexão educacional e se configura nas relações entre artista/docente e público.

Os trabalhos do Caleidos Cia. de Dança, que dirijo com Fábio Brazil em São Paulo, têm como pressuposto que artistas exercem função docente ao dançar, função docente esta que foge dos estereótipos cristalizantes do que seja um professor. Discutirei a seguir, referenciada pela produção artística da companhia desde 1996, propósitos e educação dos artistas/docentes.

O foco desta discussão não será a influência da arte na educação, ou o artista/ docente em sala de aula como já fiz em outros trabalhos, mas sim, o quanto minha formação e atuação na área de educação modificou e influenciou a atuação do artista/docente em cena. Ou: o que a arte pode aprender com a educação?

\section{Artista/docente na cena de dança: leituras}

Percebo hoje que as ações artísticas do Caleidos Cia. de Dança têm como referência e proposta explícita um estado de relações múltiplas, plurais e imanentes. A cena artística que se configura nas proposições artísticas da companhia são um campo de efetuações e possibilidades relacionais cujos protagonistas são o artista/ docente, o público e o trabalho artístico.

Lendo hoje as proposições cênicas que costuram o repertório da companhia ${ }^{3}$ vejo que elas estão intimamente ligadas a um pensar-fazer pedagógico que também guia minha carreira docente. Compreender as múltiplas e multifacetadas relações entre professor, aluno e conhecimento como redes múltiplas e mutáveis de um processo contínuo de conhecimento são pressupostos do trabalho educacional que desenvolvo desde 1990. Não é à toa, portanto, que a formação de redes de relações cênicas também esteja presente nas proposições de todos os trabalhos cênicos do Caleidos Cia. de Dança.

A formação de uma rede de relações políticas e socioafetivo-culturais que proponho em minha produção "pedagógica" (vide Marques 1989, 1996, 2010 etc.) é de fato o que estabelece as referências para os processos de criação e também as proposições cênicas dos trabalhos artísticos do Caleidos Cia. de Dança: as inter-relações propositais entre artistas (marcadas pelas proposições coreográficas), entre

\footnotetext{
3 Desde a sua fundação em 1996, o Caleidos Cia. produziu 16 espetáculos: a série 'Coreológicas' (I, II, III, IV, V, Brasil-Finland e Ludus, prêmio da Lei de Fomento à Dança 2008, 2009), 'Cidade em Trânsito' (1998), 'Silêncio' (2003), 'Gaiola!' (2004), 'Lugar Comum' (2005), 'Ares Familiares' (prêmio Programa de Ação Social do Estado de São Paulo, 2009), 'Quatro cantos' (prêmio Lei de Fomento à Dança 2009), 'Mapas Urbanos' (prêmio Lei de Fomento à Dança 2011), 'Para o seu governo' (prêmio Lei de Fomento à Dança 2011), 'Tria' (2014) com codireção de Isabel Marques e Fábio Brazil.
} 
artistas e público (marcadas pelas propostas de interatividade), entre artistas, público e as questões sociais (marcadas pela dramaturgia) são geradoras de arte.

Nos trabalhos artísticos do Caleidos Cia. de Dança, a educação se faz presente e contribui com a cena artística tendo como interlocutor o artista/docente. Em seu dançar, ou seja, em cena, o artista/docente do Caleidos Cia. estabelece, recria, propõe e articula essas redes de relações tão caras às salas de aula de dança e também à sociedade como um todo.

O primeiro princípio dessa rede de relações é, do ponto de vista educacional, extremamente simples (isso não quer dizer simplório): sem alunos não há aula. Ou seja, sem público não há dança compartilhada enquanto arte. A interatividade de diferentes formas proposta em todos os trabalhos artísticos do Caleidos Cia. faz com que o artista/docente necessariamente se relacione com o público, sem o qual a proposição cênica (coreografia) não se realiza, ou seja, não há "espetáculo".

Os artistas/docentes do Caleidos ensaiam sempre 50\% da cena, que se completa somente na presença do público, portanto, cada apresentação assume de fato uma forma diferente, pois o público nunca é o mesmo. Fica clara a presença de um pensamento/pressuposto da educação contemporânea na cena artística da companhia, pois o público é foco da construção artística e não um depósito de ideias e manifestações arbitrárias dos artistas. Poderíamos usar aqui as palavras de Paulo Freire (1983 etc.) para discutir esta proposta cênica: não se processa nas cenas de dança do Caleidos Cia. uma "educação bancária" e sim problematizadora, consciente, ativa e transformadora.

Decorre desse pressuposto que o público que vai aos espetáculos do Caleidos Cia. participe, interaja, dialogue com os artistas/docentes. Há, de fato, um chamamento consciente e explícito para que isso aconteça. A dialogicidade, tão cara a Paulo Freire (1983 etc.), é, portanto, mais um princípio educacional presente e constante nos trabalhos cênicos do Caleidos Cia. de Dança, sendo, talvez, um de seus princípios mais importantes. Não se trata, em absoluto de participar, simplesmente, o que pode ser altamente alienante e diluidor de singularidades - vide as platéias participativas dos shows populares - é interagir e construir artísticamente a cena de dança.

A dialogicidade proposta por Paulo Freire (1983 etc.) e incorporada nas cenas interativas da companhia pressupõe posturas e crenças que fazem dos artistas do Caleidos docentes em cena, artistas/docentes. A dialogicidade em cena que proponho, obviamente, tem características específicas, diferentes das propostas em salas de aula, mas atende aos princípios educacionais de que: se configura a partir de um posicionamento, busca a problematização, a escuta o outro e, acima de tudo, acredita no potencial criador daquele com quem se dialoga.

Nos trabalhos do Caleidos Cia, partimos sempre de uma proposição cênica, uma afirmação e um posicionamento corporal dançante que não visa a respostas à toa, um laissez-faire em cena, mas sim a diálogos. Diálogos que prezam a escuta dos corpos daqueles que interagem com os artistas/docentes, ou seja, diálogos corporais que prezam o público, acreditando que têm o que dizer e o que dançar a partir de seus históricos de vida e cultura corporal - em diálogo com a proposição cênica.

Os diálogos dançantes propostos pelos artistas/docentes problematizam movimentos, possibilitam escolhas, incentivam criação pessoal e coletiva e respondem às múltiplas leituras que o público fez da dança/mundo. Nesse sentido, artista e docente, docente e artista caminham absolutamente juntos, pois as proposições cênicas 
asseguram ao dançarino seu papel de artista, os alunos [público] não são deixados no infinito de seu isolamento criativo e individual. São convidados a traçar relações múltiplas e críticas entre a arte, a educação e a sociedade, o que assegura ao artista seu papel de educador. (MARQUES, 1999, p. 118)

Da proposição nasce a interação, da interação o diálogo, do diálogo uma nova cena de dança. A nova cena de dança entende que o público é cocriador da dança e não meros títeres nas mãos dos artistas, pois "a cultura consiste em criar, não em repetir" como tanto nos ensinou Paulo Freire. Nesta concepção, cabe ao artista/docente, em cena (e não antes dela, ensaiado) desvelar, instigar, descobrir caminhos para que a cena proposta seja recriada enquanto cena artística e não terapia de grupo, festa entre amigos, encontros fortuitos. Por isso,

as proposições cênicas, não antevendo finalidade, convidam os alunos [público] ao fazer reflexivo e sensível, democratizando a arte, sem, contudo, banaliza-la. O processo dialógico entre artistas/docentes e alunos [público] torna-se assim, vivo, palpável e factível. Ao conhecimento gerado por esta comunicação subjaz uma rede de significados e significações tecida nas inter-relações entre arte e sociedade (MARQUES, 1999, p. 118).

Propomos, portanto, que o grande desafio do artista/docente em cena é compreender que: ao dançar, não mostra, propõe; não apresenta, convida; não dança 'para' o público, mas 'com' ele; não ensina, educa. Todos esses são princípios caros à educação, que se tornam vitais em uma proposta artística que se propõe também política e social. Arte e educação tornam-se indissociáveis.

\section{À guisa de conclusão}

Muitas e infinitas têm sido as contribuições do sistema da arte, dos artistas e de suas proposições para reformular, repensar e ressignificar um sistema educacional retrógrado e anacrônico que aparta o artista do docente e a arte da educação.

Neste artigo rediscuto essa separação afirmando que artista e docente podem ter uma função híbrida importante e significativa não somente nos meios escolares, mas também na cena da dança, nos meios artísticos.

Ao discutir e apresentar algumas das práticas artísticas do Caleidos Cia. de Dança (as proposições cênicas) entendo que as contribuições da educação para a arte podem ser bem interessantes e geradoras de propostas artísticas diferentes das conhecidas e reconhecidas pelas convencionalidades históricas do sistema da arte.

A presença do artista/docente em cena é uma dessas propostas que modificam a cena artística, pois propõe outro tipo de relação entre artista, público e trabalho artístico, modificando o fazer/pensar/sentir da própria manifestação de dança. 


\section{Referências}

BARBOSA, Ana Mae (1991). A imagem no ensino da arte. São Paulo: Perspectiva.

BARBOSA, Ana Mae e Cunha, Fernanda (orgs.). Abordagem triangular no ensino das artes e culturas visuais. São Paulo: Cortez Editora, 2010.

BRAZIL, Fábio e MARQUES, Isabel. Arte em questões. 2ª edição. São Paulo: Cortez.

FAVARETTO, Celso. "Arte contemporânea". In PACHECO, E. (Org.). Comunicação, educação e arte na cultura infanto-juvenil. São Paulo: Loyola, 1985, p. 93-98.

FREIRE, Paulo. Pedagogia do oprimido. Rio de Janeiro: Paz e Terra, 1983.

Paulo Freire, andarilho da utopia. São Paulo: Instituto Paulo Freire, 1998.

LEBRUN, Gérard. "A mutação da obra de arte." In LEÃO, E. (Org.). Arte e filosofia. Rio de Janeiro: Funarte, 1983, p. 21-31.

MARQUES, Isabel. Dance in the curriculum: the Brazilian case. Dissertação (Mestrado). Laban Centre for Movement and Dance, 1989.

"Ensino de dança na contemporaneidade: reflexões sobre a formação do artista/docente."

Anais do I Simpósio de Pesquisa da FEUSP. Série Estudos e Documentos 1, 1994, p. 414-31.

. Dança no contexto: uma proposta para a educação contemporânea. Tese (Doutorado).

Faculdade de Educação da USP, 1996.

Ensino de dança hoje: textos e contextos. São Paulo: Cortez, 1999.

Linguagem da dança: arte e ensino. São Paulo: Digitexto, 2010a.

. "Dança-educação ou dança e educação?” In MARINHO, N.; TOMAZZONI, A. e WOSNIAK,

C. (Orgs.). Seminários de Dança 3. Blumenau: Nova Letra Gráfica e Editora, 2010b, p. 25-37. 